\title{
Treatments for elderly cancer patients and reforms to social security systems in Japan
}

\author{
Fumio Nagashima ${ }^{1}$ (D) Junji Furuse ${ }^{1}$
}

Received: 17 October 2021 / Accepted: 28 November 2021 / Published online: 31 January 2022

(c) The Author(s) under exclusive licence to Japan Society of Clinical Oncology 2021

\begin{abstract}
In Japan, the population aged 65 years and above accounts for $29 \%$ of the total population. Furthermore, the number of cancer patients among the elderly is increasing. Geriatric oncology is a discipline that deals with appropriate care for elderly cancer patients based on their characteristics. The International Society of Geriatric Oncology considers education, treatment, research, and partnership building areas of significance and priority for policy goals. In Japan, the Third Term of the Basic Plan to Promote Cancer Control is an initiative to improve the infrastructure and health services involved in cancer care. Content related to "cancer in the elderly" was added to establish guidelines for treating cancer in the elderly. Thus far, "Clinical Practice Guidelines of Cancer Drug Therapies for the Elderly" have been published. With the increasing age of the population, social security expenditures will increase substantially after the fiscal year 2022. Reforms to social security systems, such as pensions, medical care, and nursing care, are underway. It is important to enhance cooperation between oncology and geriatrics and to support cooperative systems among families and medical professionals to promote geriatric oncology. Since the working-age population and the total population have begun to decline, Japan is facing many challenges. As a leader of a super-aging society, Japan has the potential to share its experience on a global scale and address potential long-term outcomes.
\end{abstract}

Keywords Geriatric oncology $\cdot$ Geriatric assessment $\cdot$ Super-aging society $\cdot$ Social security system $\cdot$ Third term of the basic plan to promote cancer control

\section{Introduction}

The world's population is aging rapidly. According to the World Population Prospects 2019, 1 of 11 (9\%) individuals of the world's population will be aged 65 years or older by 2019 ; this number is expected to rise to 1 of $6(16 \%)$ by 2050 . Increased pressure on the social security system due to a declining proportion of the working-age population has been reported [1]. In Japan, the number of people 65 years and older is estimated to be 36.4 million in September 2021 , which is $29.1 \%$ of the total population, the highest percentage in the world [2]. The demand for medical care and long-term care is increasing, thus making it necessary to establish an appropriate system to cope with

Fumio Nagashima

fnagashi@ks.kyorin-u.ac.jp

1 Department of Medical Oncology, Faculty of Medicine, Kyorin University, 6-20-2 Shinkawa, Mitaka, Tokyo 181-8611, Japan these demands. In addition, the number of cancer patients is also increasing as the population ages. More than half of the cancer patients in developed countries are over 70 years old. It is necessary to respond to new social issues related to cancer in a super-aging society. Geriatric oncology is the discipline that addresses clinical issues such as "how to individualize treatment methods based on the risks and benefits of cancer treatment;" "how to comprehensively understand patients' health status and use it for treatment;" and "how cancer and treatment affect patients' aging," considering the characteristics of the elderly. However, this field is yet to be established, and policies are likely to differ depending on the medical situation in each country. Hence, a comprehensive discussion on the issues to be prioritized and their solutions are needed.

The International Society of Geriatric Oncology (SIOG) released a list of 10 priority initiatives to promote geriatric oncology. Since then, SIOG has revised its priority initiatives in response to advances in geriatric oncology, the growing public health challenges associated with chronic 
diseases, such as cancer, the WHO's focus on non-communicable diseases, and the UN's adoption of the 2030 Agenda for Sustainable Development Goals in 2015 [3]. A total of 12 priorities were established, with focus areas including education, clinical care, research, and partnership building (Table. 1). In Japan, the Cancer Control Act, wherein the Ministry of Health, Labour and Welfare formulated a draft of a "Basic Plan to Promote Cancer Control Programs" with input from the Cancer Control Promotion Council, was instituted; however, there were no specific plans to address geriatric oncology. For the first time, the Third Term of the Basic Plan to Promote Cancer Control addressed "cancer in the elderly" as an individual goal in Japan [4]. This paper will discuss geriatric oncology in Japan, individual goals included in the Third Term of the Basic Plan to Promote Cancer Control, domestic and international guidelines, efforts and future possibilities of social security systems, and oncology in a super-aging society.

\section{Geriatric assessment}

SIOG mentioned that education programmes for health-care professionals should include changes in cancer and patient biology and function with aging, the value of a geriatric assessment as an effective methods [3]. Comprehensive geriatric assessment (CGA) can provide comprehensive medical care by assessing the physical, mental and social functions of patients. This approach has been established in the field of geriatrics and shown to improve mortality rates and readmission rates. CGA is also recommended in oncology setting [5]. Domains of geriatric assessment are consist of physical function [6-9], comorbidities [10-14], medications [15, 16], cognitive function [17, 18], mood [19], nutritional status [20], social support and geriatric syndrome (falls, osteoporosis, loss of hearing, etc.) [5, 21, 22].

Despite the fact that GA is recommended in geriatric oncology guidelines, GA and its management are still not common in cancer treatment. One reason for this is the paucity of data showing improved outcomes in cancer treatment. In general, elderly patients often focus on reducing the risk of adverse events and maintaining normal life and quality of life as goals of advanced cancer treatment [23, 24]. More recently, Mohile et al. reported that providing GA and its management to elderly patients undergoing chemotherapy for advanced solid tumors can help reduce serious adverse events [25]. In Japan, a clinical trial is underway with the endpoint of improving patient satisfaction and treatment outcomes by providing GA with management in non-small cell lung cancer [26].

\section{Third term of the basic plan to promote cancer control and its regard for geriatric oncology}

The Third Term of the Basic Plan to Promote Cancer Control was approved by the Cabinet in March 2018 and included measures to deal with cancer in the elderly. As measures to be implemented, the plan states the following: "Research should be conducted to establish treatment methods and guidelines suitable for elderly cancer patients, including from a QOL perspective, and cooperation should be requested from relevant academic societies to formulate medical treatment guidelines for elderly cancer patients in

Table 1 Priorities SIOG updated for the advancement of oncology for older adults

\section{Education}

1) Integrate geriatric oncology into medical, nursing, and allied health professionals programs both in schools and residency trainings

2) Provide educational materials and organize educational activities

3) Educate the general public about the provision of age-appropriate cares for older adults with cancer

Clinical practice

4) Develop and implement o models to provide optimal care for older adults with cancer

5) Develop guidelines for the optimal treatment of older adults with cancer

6) Establish centers of excellence in geriatric oncology for delivering care, conducting clinical and translational researches, and providing educational opportunities

Research

7) Improve the relevance of clinical trials to older adults with cancer

8) Evaluate the benefits of geriatric assessment-allocated treatments and geriatric comanagement in improving treatment outcomes for alder adults with cancer

9) Use personalized medicine technologies to enhance cancer understanding and management of older adults

Collaboration and partnerships

10) Develop and strengthen links between SIOG and the geriatric oncology workforce, international specialized agencies, global and regional professional organizations, policy makers, and patient advocacy groups

11) Promote the inclusion of specific provisions for delivering high-quality, evidence-based care for older adults in national cancer control plans

12) Create global funding mechanisms aimed at fostering professional development of the geriatric oncology workforce and promoting research on the interface of cancer and ageing

(From references [3], partially altered by authors) 
order to incorporate the perspective of elderly care into the current medical treatment guidelines for each cancer type in the future"; "The Government of Japan will formulate measures to support the decision-making of cancer patients with dementia and elderly cancer patients in the end-of-life care period. In order to support elderly cancer patients, the government will implement measures to support the medical treatment life of patients and their families in accordance with their decision-making through cooperation among doctors, medical professionals, and caregivers at medical institutions and nursing homes." It has been clearly stated as individual goals that guidelines should be established and disseminated to hub hospitals. Based on the basic plan, various studies have been conducted with assistance from the Ministry of Health, Labor and Welfare (MHLW) and the Agency for Medical Research and Development (AMED). Preparations are underway to formulate guidelines. Guidelines for the treatment of cancer in the elderly have already been published overseas. Excerpts from these publications will be introduced below.

\section{National comprehensive cancer network (NCCN) guidelines for geriatric oncology}

The following process is described as the concepts of cancer treatment for the elderly [22]:

1) Estimate life expectancy: In Japan, data on life expectancy by age and general condition provided by the Cancer Information Service of the National Cancer Center can be used as a reference, considering that life expectancy differs greatly depending on overall health not just age [27].

2) Assess the patient's decision-making capacity: The assessment of decision-making ability is based on the following four items: (a) understanding: being able to understand the medical examinations and treatments proposed by the physician; (b) awareness: being able to understand the current situation (medical situation, causes of illness, etc.) as it relates to oneself; (c) logical thinking: being able to logically compare the risks and benefits of treatment options proposed by the physician; and (d) expression of choice: being able to express one's choice verbally or by other means.

3) Identify the patient's wishes and values regarding treatment: Check their compatibility with the treatment details proposed by medical professionals.

4) Risk assessment: Objectively assess comorbidities, degree of geriatric syndromes, and confirmation of social and economic problems. Geriatric assessment should be performed within this process.

5) Propose treatment: A treatment is proposed based on risk assessment. Dose modification and supportive care should be considered.

\section{ASCO Geriatric oncology guidelines}

In 2018, the American Society of Clinical Oncology (ASCO) released guidelines on "Practical Assessment and Management of Vulnerabilities in Older Patients Receiving Chemotherapy" [21]. It states that "patients 65 years of age or older who are starting chemotherapy should undergo geriatric assessment (GA) to identify routinely undetected vulnerabilities," and recommends that GA should include assessment of (1) physical function, (2) falls, (3) comorbidities, (4) depression, (5) cognitive function, and (6) nutrition. It also recommends that the Cancer and Aging Research Group (CARG) score [28] and Chemotherapy Risk Assessment Scale for High-Age Patients (CRASH) score [29] be used to predict the side effects of chemotherapy. The G8 and VES-13 can be used to predict prognosis [30-33]. Table 2 shows the specific assessment methods and the interventions provided in the American Society of Clinical Oncology guidelines.

Table 2 Recommended geriatric oncology tools and interventions (from reference [21], partially altered by authors)

\begin{tabular}{|c|c|c|}
\hline Evaluating items & Tools for functional assessment of the older adults & Examples of intervention \\
\hline $\begin{array}{l}\text { Predicting side } \\
\text { effects of chemo- } \\
\text { therapy }\end{array}$ & CARG score or CRASH score & Modification of dose-intensity \\
\hline Physical function & IADL (Instrumental activity of daily living) & Accommodation with mobility aids, meal catering, etc \\
\hline Comorbidity & $\begin{array}{l}\text { Detailed medical history, Charlson Comorbidity Index (CCI), } \\
\text { Cumulative Illness Rating Scale (CIRS) }\end{array}$ & Referral and liaison to each comorbidity specialists \\
\hline Falls & Number of falls in the past 6 months & Physiotherapy, occupational therapy, mobility aids \\
\hline Depression & GDS (Geriatric Depression Scale) & $\begin{array}{l}\text { Antidepressant medicine, cognitive-behavioral therapy, or } \\
\text { other psychotherapy }\end{array}$ \\
\hline Cognitive function & $\begin{array}{l}\text { Mini-Cog or BOMC (Blessed Orientation Memory Concen- } \\
\text { tration) test }\end{array}$ & $\begin{array}{l}\text { Memory support aids like memorandum and text message } \\
\text { reminders }\end{array}$ \\
\hline Nutrition & BMI (Body Mass Index) & Nutrition counseling \\
\hline
\end{tabular}


Although these methods have not been established in Japan, it is possible to use screening tools such as G8, a screening tool that is already being used clinically in Japan, as well as devise cognitive function assessments, along with long-term care insurance.

\section{Guidelines for medical treatment in Japan}

The Japanese Society of Medical Oncology and the Japan Society of Clinical Oncology, with the cooperation of the Japanese Geriatrics Society, published "Clinical Practice Guidelines of Cancer Drug Therapies for the Elderly" in July 2019 [34]. Nurses, pharmacists, patients, and the public were added to the recommendation panel to ensure non-physician perspectives were included. Although the number of CQs is limited to 15, this is the first Medical Information Distribution Service in Japan (Minds)-based guidelines for treating cancer in the elderly. Although it covers only five representative carcinomas, does not have high levels of evidence, and does not discuss supportive and symptomatic therapies, it is still a good reference for the concept of cancer pharmacotherapy in the elderly. In response to the CQ, "Is functional assessment of the elderly recommended as a method of determining the indication for cancer drug therapy?" the guideline states that "its implementation is suggested" [34].

In addition, although not considered as a guideline, the Japanese Association for Supportive Care of Cancer took the lead in preparing a Q\&A on cancer care for the elderly. The content was compiled by experts, including useful information for practical treatment.

\section{Initiatives for a social security system to support the elderly}

Approximately $15 \%$ of medical costs for the elderly over 65 years of age are for neoplasms (tumors) [35]. The social security system that supports medical expenditure has the following issues since the recent revisions in the law. The issues are outlined below:

1) Future demographic changes and increases in medical costs for the elderly

The state of the social security system depends on changes in the composition of the population. Today Japan is already in a phase of population decline because of the lower birth rate. The elderly population (65 years and above) will increase rapidly by 2025 , which will stay consistent over the next 40 years. In contrast, the working-age population (15-64 years old), which supports the elderly, has been declining and will be reduced to $2 / 3$ of its current level by the next 40 years.

Elderly individuals inevitably require medical care as they get older. Therefore, a future increase in the elderly population will lead to an increase in their medical costs. We need to consider that the so-called baby boomers, born between 1947 and 1949, will enter the late elderly stage between 2022 and 2024. Thus, how to support the large increase in medical expenses for the elderly will become an issue.

2) Composition of financial resources for the elderly healthcare system and increase in burden for the workingage population

From society's perspective of supporting the medical care of the elderly, the cost of medical benefits under the latestage medical care system for the elderly is approximately $10 \%$ for the elderly, $40 \%$ for the working-age population and $50 \%$ for the public funds. The cost of medical care for the working-age population is covered by insurance premiums from various health insurances through their employer or private insurance. In other words, the working-age population contributes money yearly to support the medical cost of the elderly. The increase in the burden on the working-age population is a major issue at present.

3) Basic direction of all-generation social security reform and bill to revise the medical care system for the elderly

Considering the era of 100 year life spans, the government is promoting social security reforms that include work habits for all generations. In other words, the government is promoting reforms for pensions, medical care, nursing care, and social security in general. They focus on changes in the way we work while positively viewing the increase in longevity as an opportunity. By doing so, the government is envisioning a social security system that will provide support for all generations, while keeping an eye on the future of Japan by limiting the rising burden on the working-age population [36].

Regarding the medical care system for the elderly, in response to the aforementioned issues, a review of the copayment ratio for the late-stage elderly was considered. An amendment bill that would raise the proportion of the burden borne at the counter to $20 \%$ for late-stage elderly with a lower income, excluding those with an income comparable to that of the working-age population, was submitted to the Diet in 2021 and was enacted in June 2021. The effective date of this bill is to be determined by a Cabinet Order in the latter half of 2022, considering the preparation period required for system renovation [37].

4) Approach to review the proportion of the burden borne by the elderly at the counter

As baby boomers begin to reach 75 years and above from 2022, medical costs for the late-stage elderly will increase, 
whereas the number of working-age people to support them will decrease. If this trend continues, the burden on the working-age population will increase from 6.8 trillion yen in fiscal year 2021 to 7.1 trillion yen in 2022 and 8.1 trillion yen in 2025. In the short term, the burden on the workingage population is expected to rise even higher than before. For this reason, the main pillar of the government's approach is to reduce the growth of the burden of the support payment for the late-stage elderly by setting the over-the-counter payment at $20 \%$ for those with an income above a certain level ( 2 million Yen to 3.83 million Yen) who can bear the burden and to reduce insurance premiums on the working-age population as much as possible.

5) Comprehensive considerations going forward.

To build a sustainable social security system, it is necessary to continue to have reforms. Hence, a provision for consideration has been included in Article 2 of the Supplementary Provisions of the revised law.

The House of Councilors, in its supplementary resolution, called for "a comprehensive discussion, including taxation, to be initiated on how the burden should be based on ability, such as raising the maximum amount of insurance premiums, how insurance benefits should be provided, and how the appropriate balance should be struck between insurance premiums, public expenses, and self-pay in financing medical expenses."

Amid the financial difficulties of dealing with the novel coronavirus pandemic, it is necessary to have careful discussions with a wide range of stakeholders from a range of perspectives, with a focus on 2040.

\section{State of insurance benefits for cancer drug therapy}

With advancements in medical technology, the development of innovative new cancer drug therapies that are highly effective has been progressing. Concurrently, the extremely high medical cost of these drugs has become a significant burden on medical insurance finances and, ultimately, the public. Thus, the government decided to implement the following measures as listed in the basic policy for the fundamental reform of the National Health Insurance Drug Price Standard decided at the end of 2016 to deal with medical fees:

- To respond promptly to market expansion above a certain level due to additional indications; medical fees will be reviewed four times a year, taking full advantage of opportunities for new drug listings.

- To reflect the prevailing market prices in drug prices promptly and reduce the burden on the public, an annual drug price survey was conducted for all products, and drug prices were revised based on the results.
- To promote R\&D investment, truly effective drugs are properly identified, and innovation is evaluated through the full-scale introduction of cost-effectiveness assessments.

Since April 2019, a cost-effectiveness assessment system has been implemented.

The revision of medical fees is scheduled for April 2022, and the basic policy for the revision is currently being discussed by the Medical Insurance Committee of the Social Security Council to meet this timeframe. The setting of points and cost calculation for individual medical fee items are discussed by the Chuikyo (Central Social Insurance Medical Council).

\section{Conclusion}

The International Society of Geriatric Oncology has proposed a list of priority issues that must be addressed and measures that must be taken to advance geriatric oncology. While the priorities and policies differ between developed countries and other regions, the perspectives of education, medical care, research, and partnership building are common. In Japan, reforms in pensions, health care, nursing care, and social security, in general, are underway, with a focus on changes in the general work habits. A multidimensional response is urgently needed. In the treatment of cancer in the elderly, it is important to further enhance corporation between oncology and geriatrics, as well as for families and medical professionals to support the elderly at various levels. In geriatric oncology, it is necessary to develop individualized treatment approaches that consider the diversity of patients by promoting cooperation with other fields and the development of community environments where people can live with peace of mind.

Meanwhile, many issues are coming to the surface in Japan, where the working-age and total populations have begun to decline. Japan's experience as a leader in a superaging society can be shared on a global scale and should be considered from a long-term perspective.

Acknowledgements Authors would like to thank Kentaro Enomoto, Ministry of Health, Labour and Welfare for special comments in terms of social security systems in Japan.

Author contributions All authors contributed to the study's conception and design. Material preparation, data collection, and analysis were performed by FN and JF. The first draft of the manuscript was written by FN and all authors commented on previous versions of the manuscript. All authors read and approved the final manuscript.

Funding This work was supported by JSPS KAKENHI Grant Number JP20K12049. 


\section{Declarations}

Conflict of interest The authors declare that they have no actual or potential conflicts of interest to declare.

\section{References}

1. Information UNCfP (2019) World population estimates. Available from: https://www.unic.or.jp/news_press/info/33789/. Accessed Oct 2021

2. Statistics Bureau MoIAaC (2021) Population of the elderly. Available from: http://www.stat.go.jp/data/topics/topi1291. html. Accessed Oct 2021

3. Extermann M et al (2021) Priorities for the global advancement of care for older adults with cancer: an update of the International Society of Geriatric Oncology Priorities Initiative. Lancet Oncol 22(1):e29-e36

4. Ministry of Health L.a.W (2018) Third term of the basic plan to promote cancer control. Available from: https://www.mhlw.go. jp/file/06-Seisakujouhou-10900000-Kenkoukyoku/0000196975. pdf. Accessed Oct 2021

5. Wildiers H et al (2014) International Society of Geriatric Oncology consensus on geriatric assessment in older patients with cancer. J Clin Oncol 32(24):2595-2603

6. Katz S et al (1963) Studies of illness in the aged. the index of adl: a standardized measure of biological and psychosocial function. JAMA 185:914-919

7. Balducci L, Beghe C (2000) The application of the principles of geriatrics to the management of the older person with cancer. Crit Rev Oncol Hematol 35(3):147-154

8. Wedding U et al (2007) Physicians' judgement and comprehensive geriatric assessment (CGA) select different patients as fit for chemotherapy. Crit Rev Oncol Hematol 64(1):1-9

9. Lawton MP (1988) Scales to measure competence in everyday activities. Psychopharmacol Bull 24(4):609-614

10. Extermann $M$ (2007) Interaction between comorbidity and cancer. Cancer Control 14(1):13-22

11. Pal SK, Hurria A (2010) Impact of age, sex, and comorbidity on cancer therapy and disease progression. J Clin Oncol 28(26):4086-4093

12. Charlson ME et al (1987) A new method of classifying prognostic comorbidity in longitudinal studies: development and validation. J Chronic Dis 40(5):373-383

13. Linn BS, Linn MW, Gurel L (1968) Cumulative illness rating scale. J Am Geriatr Soc 16(5):622-626

14. Frasci $\mathrm{G}$ et al (2000) Gemcitabine plus vinorelbine versus vinorelbine alone in elderly patients with advanced non-smallcell lung cancer. J Clin Oncol 18(13):2529-2536

15. Maggiore RJ, Gross CP, Hurria A (2010) Polypharmacy in older adults with cancer. Oncologist 15(5):507-522

16. Turner JP et al (2016) Polypharmacy cut-points in older people with cancer: how many medications are too many? Support Care Cancer 24(4):1831-1840

17. Folstein MF, Folstein SE, McHugh PR (1975) "Mini-mental state". A practical method for grading the cognitive state of patients for the clinician. J Psychiatr Res 12(3):189-198

18. Borson S et al (2003) The mini-cog as a screen for dementia: validation in a population-based sample. J Am Geriatr Soc 51(10): 1451-1454

19. Blessed G, Tomlinson BE, Roth M (1968) The association between quantitative measures of dementia and of senile change in the cerebral grey matter of elderly subjects. Br J Psychiatry 114(512):797-811

20. Alexandre $\mathbf{J}$ et al (2003) Evaluation of the nutritional and inflammatory status in cancer patients for the risk assessment of severe haematological toxicity following chemotherapy. Ann Oncol 14(1):36-41

21. Mohile SG et al (2018) Practical assessment and management of vulnerabilities in older patients receiving chemotherapy: ASCO guideline for geriatric oncology. J Clin Oncol 36(22):2326-2347

22. NCCN Guidelines Version 1 (2021) Older Adult Oncology National Comprehensive Cancer Network. https://www.ncen. org/professionals/physician_gls/pdf/senior.pdf

23. Mohile SG et al (2020) Communication with older patients with cancer using geriatric assessment: a cluster-randomized clinical trial from the national cancer institute community oncology research program. JAMA Oncol 6(2):196-204

24. Battisti NML et al (2021) Bridging the age gap in breast cancer: Impact of chemotherapy on quality of life in older women with early breast cancer. Eur J Cancer 144:269-280

25. Mohile SG et al (2021) Evaluation of geriatric assessment and management on the toxic effects of cancer treatment (GAP70+): a cluster-randomised study. Lancet. https://doi.org/10.1016/ S0140-6736(21)01789-X

26. Tsubata $Y$ et al (2021) Protocol for a multi-site, cluster-randomized, phase III, comparative clinical trial of geriatric assessment of older patients with non-small-cell lung cancer: the ENSURE-GA study. BMC Geriatr 21(1):74

27. Iwamoto M, Nakamura F, Higashi T (2014) Estimated life expectancy and risk of death from cancer by quartiles in the older Japanese population: 2010 vital statistics. Cancer Epidemiol 38(5):511-514

28. Hurria A et al (2016) Validation of a prediction tool for chemotherapy toxicity in older adults with cancer. J Clin Oncol 34(20):2366-2371

29. Extermann $M$ et al (2012) Predicting the risk of chemotherapy toxicity in older patients: the chemotherapy risk assessment scale for high-age patients (CRASH) score. Cancer 118(13):3377-3386

30. Soubeyran P et al (2014) Screening for vulnerability in older cancer patients: the ONCODAGE prospective multicenter cohort study. PLoS ONE. https://doi.org/10.1371/journal.pone. 0115060

31. Kenis C et al (2014) Performance of two geriatric screening tools in older patients with cancer. J Clin Oncol 32(1):19-26

32. Owusu $C$ et al (2017) Short physical performance battery, usual gait speed, grip strength and Vulnerable Elders Survey each predict functional decline among older women with breast cancer. J Geriatr Oncol 8(5):356-362

33. Biganzoli L et al (2017) Screening for frailty in older patients with early-stage solid tumors: a prospective longitudinal evaluation of three different geriatric tools. J Gerontol A Biol Sci Med Sci 72(7):922-928

34. Japanese Society of Medical Oncology (2019) Clinical practice guidelines of cancer drug therapies for the elderly. Nankodo, Tokyo

35. Heisei 30 nenndo Kokumin iryohi no gaikyo (in Japanese) Ministry of Health, Labour and Welfare of Japan.https://www.mhlw. go.jp/toukei/saikin/hw/k-iryohi/18/dl/data.pdf

36. Japan, P.M.s.O.o (2020) Council for the Study of Social Security for All Generations. Available from: https://www.kantei. go.jp/jp/singi/zensedaigata_shakaihoshou/dai12/gijiroku.pdf. Accessed Oct 2021

37. Council t.M.o.t.M.I.C.o.t.S.S (2021) Bill for Partial Amendment to the Health Insurance Act, etc. for the Purpose of Establishing a Social Security System for All Generations. Available from: https://www.mhlw.go.jp/content/12401000/000739687. pdf. Accessed Oct 2021

Publisher's Note Springer Nature remains neutral with regard to jurisdictional claims in published maps and institutional affiliations. 